\title{
Vibrio Cholera Diarrhea in One Day Old Newborn with a Favorable Outcome: A Case Report
}

\section{Shivani Deswal ${ }^{\star}$, Murtaza Kamal and Swati Girdhar}

Department of Pediatrics, Safdarjung hospital \& V.M.M.C, New Delhi, India

"Corresponding author: Shivani Deswal, Department of Pediatrics, Safdarjung hospital \& V.M.M.C, New Delhi, India, Tel: 011-26897022; E-mail: shivanipaeds@gmail.com

Rec date: Apr 15, 2014; Acc date: Apr 19, 2014; Pub date: May 01, 2014

Copyright: () 2014 Deswal S, et al. This is an open-access article distributed under the terms of the Creative Commons Attribution License, which permits unrestricted use, distribution, and reproduction in any medium, provided the original author and source are credited.

\begin{abstract}
Cholera may be clinically indistinguishable from other common causes of severe diarrhea in neonates. The most common worldwide form is Vibrio cholera El Tor. A delay in diagnosis can lead to high fatality rates due to renal failure and seizures. Hanging drop method for diagnosis has $100 \%$ specificity. In India youngest age reported is a 3 day old baby. We report a case of Vibrio Cholera gastroenteritis with hyponatremic dehydration with pre renal ARF in one day old newborn.
\end{abstract}

\section{Introduction}

Gastroenteritis in newborns is not an uncommon entity. They are at increased risk of complications related to diarrhea due to immaturity of the systems that regulates fluid homeostasis and immunologic response [1]. We report a case of Vibrio Cholera gastroenteritis with hyponatremic dehydration with pre renal ARF in one day old newborn.

\section{Case Report}

Male baby was born to 23 yrs old, booked and immunized G2 P1 L1 mother with term pregnancy with no sepsis setting (UTI, diarrhea) by vaginal delivery and required positive pressure ventilation for 30 seconds so was transferred to nursery for post resuscitation care. Baby was low birth weight $(2.2 \mathrm{~kg})$ with respiratory distress (TTNB) which settled in 4 hours. At 24 hours of life, he developed loose watery stools and vomiting leading to severe dehydration. Possibility of Early Onset Sepsis with E. Coli was kept and correction of severe dehydration was done by N/2 in $5 \%$ dextrose $(30 \mathrm{ml} / \mathrm{kg}$ in 1 hour followed by $70 \mathrm{ml} / \mathrm{kg}$ over 5 hours) and antibiotics started. ABG showed $\mathrm{pH}=7.35, \mathrm{pO}_{2}=88$ $\mathrm{mmHg}, \mathrm{pCo}_{2}=38 \mathrm{~mm} \mathrm{Hg}, \mathrm{HCO}_{3}=20 \mathrm{mmol} /, \mathrm{BE}=-5 \mathrm{mmol} / \mathrm{L}$, blood sugar-110 mg\% , S.Na- $113 \mathrm{meq} / \mathrm{l}$, S.K -3.4 meq/l. Hb -19 gm/dl, TLC -8200 cells/cu.mm P 75 L 15, P/C-1.2 lakh/cu mm, CRP-positive, P/-S no evidence of sepsis and blood culture was sterile. CSF was normal while Serum creatinine was $3.8 \mathrm{mg} / \mathrm{dl}$ and Blood urea $70 \mathrm{mg} / \mathrm{dl}$. At 30$50 \mathrm{hrs}$ of life, baby continued to have high purge rate requiring continued fluid replacement. Stool routine microscopy showed darting motility suggestive of Vibrio Cholera which was later confirmed on culture, so injection Ciprofloxacin was started. Day 4 to Day 7, baby improved significantly; KFT and electrolytes normalized and was discharged on Day 10 of life. Epidemiological investigation revealed no illness with diarrhea in the patient's mother or other close contacts. Rectal Swab and vaginal swab of nursery staff and mother were negative for V.Cholera. No other baby in Nursery had diarrhea subsequently.

\section{Discussion}

Cholera may be clinically indistinguishable from other common causes of severe diarrhea in neonates like Enterotoxigenic E. coli and Rotavirus gastroenteritis. It should be suspected in newborns with high purge rate of diarrhea and vomiting especially in endemic areas. Stool is typically rice water type. It can lead to severe dehydration and shock within hours [2]. In India youngest age reported is a 3 day old breastfed baby from Delhi, India [1]. ETEC and rotavirus lead to less severe watery diarrhea and vomiting and the latter is generally associated with low grade fever [2]. Early diagnosis \& timely treatment is crucial in neonates. Transmission can be during labor, through symptomatic mother /asymptomatic carrier mother, holy water (charnamrit), top feeds, pre lacteals, family members (chronic carrier) or nosocomial (hospital staff). Cholera spreads from person to person through hands, bed sheets, and other linen or from food which has been handled by a carrier. Contaminated water can transmit the disease as there is no maternally transmitted immunity $[3,4]$. It has never been found to be transmitted by mother's milk [1]. Culture in selective media TCBS agar remains the gold standard however it cannot be awaited for initiation of treatment. Hanging Drop with darting motility has positive predictive value of $100 \%$ [5]. Rehydration is the mainstay of therapy [2]. Ciprofloxacin is currently the drug of choice in newborns. It is best to isolate the baby to prevent outbreak. Close monitoring of status of hydration and severity of purging is desired. Severely dehydrated patients require replacement of $10 \%$ of their body weight within 2-4 hours followed by replacing continuing fluid losses until diarrhea stops. Efforts should be made to identify the source to limit the outbreaks. Nursery staffs do not need prophylaxis but must be particularly careful about washing hands and all contaminated clothing. With early and adequate treatment, case fatality rate is about $1 \%$ while it is $50 \%$ without adequate treatment.

\section{References}

1. Sethi NK, Sethi SK ( 2001) Vibrio cholerae diarrhoea in a three-day-old breastfed neonate. Indian Journal of Pediatrics 68: 791-792.

2. Bhutta ZA (2012) .Acute gastroenteritis in children. In: Keiegman RM, Behram RE, Jenson B, (19thedn). Nelson Textbook of Pediatrics, Saunders, Philadelphia. 
Citation: Deswal S, Kamal M, Girdhar S (2014) Vibrio Cholera Diarrhea in One Day Old Newborn with a Favorable Outcome: A Case Report. J Neonatal Biol 3: 140. doi:10.4172/2167-0897.1000140

Page 2 of 2

3. Khan AM, Bhattacharya MK (1995) Neonatal diarrhoea caused by Vibrio cholerae 0139 Bengal. Diagnostic Microbiology and Infectious Disease 23: $155-156$.

4. Coovadia YM, Bhamjee A, Isaäcson M (1983) Vibrio cholerae bacteraemia newborn infant. S AIr Med J 64: 405-406.
5. Uppal B, Berry N (1999) TI Vibrio cholera 01 serotype Ogawa in a neonate. Diagnostic Microbiology and Infectious Disease 33: 63-64 